\title{
TECHNOLOGICAL ASPECTS REGARDING THE MANUFACTURE OF SCREW-RETAINED PROSTHETIC RESTORATIONS MADE OF CERAMIC MASSES ON ZIRCONIA STRUCTURE (PART I)
}

\author{
RADU COSTEA ${ }^{1}$, MĂDĂLINA VIOLETA PERIEANU ${ }^{2}$, MAGDALENA NATALIA DINA ${ }^{3}$, MIHAI \\ BURLIBAȘA ${ }^{4}$, IRINA ADRIANA BEURAN ${ }^{5}$, DANA CRISTINA BODNAR ${ }^{6}$, CAMELIA IONESCU ${ }^{7}$, \\ ŞTEFẢN MILICESCU ${ }^{8}$, NICOLETA MĂRU ${ }^{9}$, GABRIELA TĂNASE $^{10}$, ELENA-CRISTINA \\ MARCOV $^{11}$, IULIANA BABIUC ${ }^{12}$, NARCIS MARCOV ${ }^{13}$, \\ MIHAI BUTUCESC ${ }^{14}$, LILIANA MORARU ${ }^{15}$ \\ 1,2,3,4,5,6,7,8,9,10,11,12,13,14 “'Carol Davila” University of Medicine and Pharmacy, Bucharest, \\ 15 “Titu Maiorescu” University of Medicine and Pharmacy, Bucharest
}

Keywords: maximum 5 implant-prosthetic rehabilitation, screwretained prosthetic restorations, Zirconia, ceramic masses
Abstract: With the help of dental implants, an oral rehabilitation can be performed not only very complex, but also very complete of various types of edentulous spaces. After insertion of the dental implants, they can be subsequently prosthetically restored through a wide range of implant-supported prosthetic restorations. In this material, we tried to highlight some particular aspects from the point of view of the laboratory stages of dental technique, which intervene in the technological flow of making implant-supported prosthetic restorations from ceramic masses on Zirconia structure.

\section{INTRODUCTION}

Restoring the continuity of the dental arch is essential for the integrity of the dento-maxillary system and its functions. The main functions of the dento-maxillary system are mastication, phonation and physiognomy.

By mastication is meant incision and grinding of food. The roles of mastication are the appreciation of food quality, the onset of taste, the stimulation of gastric secretions and the formation of the food bowl. In the absence of masticatory units, food is no longer crushed and ground properly, which can lead to damage to the digestive tract and the appearance of diseases such as gastritis, colitis, ulcers, etc. Teeth with major coronary or root destruction also led to difficulty in mastication.(1-4)

From the point of view of the phonetic function, in the pronunciation of vowels and consonants an important role is played by: larynx (through the vocal cords), tongue, teeth and lips. The lack of teeth leads to speech impairment due to the difficulty of pronouncing words, increasing the volume of the tongue and reducing the support of the lips. Difficulty in verbal expression can have an emotional and psychological impact on totally or partially edentulous patients and can lead to their exclusion from social groups.

The physiognomic function of the dento-maxillary system has a very important role today. A neat and harmonious smile increases patients' respect and self-confidence and facilitates the formation of new interpersonal relationships. The masticatory units make a great contribution in maintaining the contours and anatomical face levels. In the absence or destruction of one or more teeth on the dental arches, physiognomic and morphofunctional disorders occur; patients in this category make efforts to change their facial expressions and have difficulty integrating into society.

\section{AIM}

As for oral implantology, it is rather an allencompassing term. In general, we are actually talking about implant-prosthetic rehabilitation, or more precisely, about oral rehabilitation through implant-prosthetic (or implant-supported) restorations of any kind, a term that in dentistry represents a succession of treatment methods, with clinical stages, extremely laborious techniques, but, at the same time, and very complex, from almost all points of view:(1-14)

Very extensive experience from the medical team: implant specialist, prosthetic specialist and dental technician;

Complex operations both in the clinical department, represented by the dental office (with both segments: surgical and prosthetic), and in the technical department, represented by the dental laboratory;

A perfect communication between the 2 compartments: clinical and technical. If this communication between the compartments is deficient, the whole process of implantprosthetic rehabilitation, or more precisely, the technological flow of implant-supported restorations, suffers;

A very extensive technical-material endowment, which should fully cover all the therapeutic implants of implantprosthetic rehabilitation;

Very high costs both from a material point of view and from the point of view of time consumed, from a physical and mental point of view;

Based on these considerations, this study will highlight some particular aspects from the point of view of the

${ }^{3}$ Corresponding author: Magdalena Natalia Dina, Str. Plevnei, Nr. 19, Sector 1, București, România, E-mail: mburlibasa@ gmail.com, Phone: +40723 472632

Article received on 22.07.2021 and accepted for publication on 02.09.2021 


\section{CLINICAL ASPECTS}

laboratory stages of dental technique, which intervene in the technological flow of making screw-retained prosthetic restorations on dental implants from ceramic masses on the structure of Zirconia.

\section{MATERIALS AND METHODS}

For many patients who have partially or completely lost their teeth, the insertion of dental implants may be the only possibility to anchor implant-supported prosthetic restoration, fixed or mobilizable with improved stability. These types of implant-supported prosthetic restorations have demonstrated over time their psychological, but especially functional, qualities that can benefit their users: a very efficient diet due to a proper chewing process, a flawless phonation, a more than satisfactory physiognomy, the patient being able to smile and laugh without restrictions, in a word, a state of well-being of the patient manifested by satisfaction and gratitude. In fact, there is a real substantial improvement in the quality of life among these patients.(1-9)

Dental crowns or bridges can be cement-retained or screw-retained to dental implants. Both options have advantages and disadvantages.

Regarding the types of implant-prosthetic restorations used in the current practice of dentistry in Romania, they can be:(1-14)

fixed cement-retained structures, with the advantage of being cheaper constructions, but with very limited possibilities to control dental implants, from a mechanical point of view;

mobilizable structures, but which have increased stability, due to special systems, with fixation by means of dental implants: ball attachments, vertical clips, bars attachments, etc.

conditionally removable superstructures, with a good possibility to control dental implants. These types of implant-supported prosthetic restorations have, as major disadvantages, very high construction costs, very laborious manufacturing technology, as well as the presence of fixing screws that sometimes interfere with occlusal contacts and sometimes can reduce the aesthetic factor.

Basically, the article will focus on the technology of creating prosthetic restorations from the last presented category.

\section{RESULTS AND DISCUSSIONS}

\section{Clinical case presentation}

Patient Y.J. presented to the dentist's office, expecting the restoration of the lost central incisor from quadrant 1 and the lateral incisor from the same quadrant, which had coronary damage. Following the clinical and radiological consult, the dentist established the treatment plan, which consisted in restoring the central incisor with the use of a ceramic crown on a Zirconia structure screw-retained on the implant. The lateral incisor will be restored with a ceramic crown on the Zirconia structure that will cover the natural abutment, the tooth remaining vital.

After performing the characteristic medical investigations and choosing the dental implant, the dentist performed the surgical operation of inserting the implant. The healing cap was fixed over the implant and waited 6 months for the implant to osseointegration. The preliminary maxillary impression with irreversible hydrocolloid (alginate) was taken in a standard impression tray, after which the preliminary cast was made in the dental laboratory. The preliminary cast was made of class 2 dental stone using the vacuum mixer and the vibrating table. An open individual impression tray was made on the preliminary cast.

The maxillary functional impression was taken by the dentist with a polyether (Impregum) in the individual impression tray, with the transfer abutment fixed on the implant. After the setting of the impression material, the transfer abutment was unscrewed, remaining fixed in the impression material.

The functional impression of the mandible was taken with silicone of putty and fluid consistency in a standard impression tray. The occlusion was recorded with a putty silicone material.

In the dental laboratory, the impression was washed and disinfected. The implant analog was fixed in the transfer abutment. Gingifast elastic was applied in the impression around to the implant. The master cast were made using the vacuum mixer and the vibratory table, with class 4 dental stone.

The master casts with mobilizable abutments were made using the Giroform technique (from Amann Girrbach) and mounted in the Amann Girrbach articulator, respecting the inter occlusal record.

\section{Figure no. 1. Master casts mounted in the articulator}

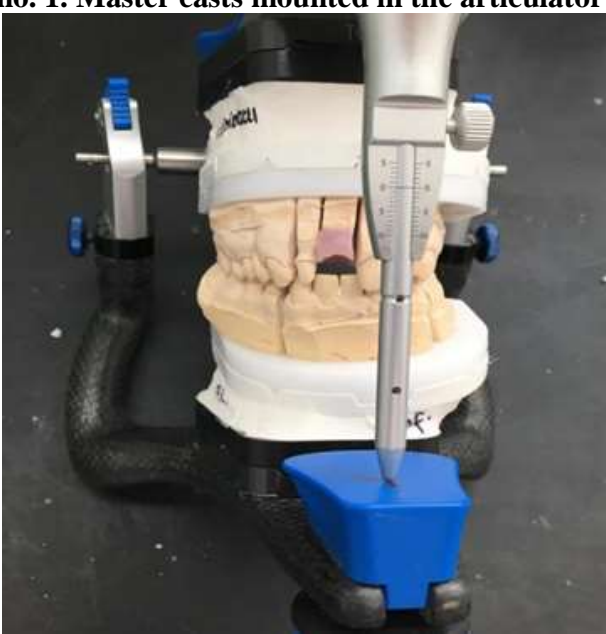

The chosen prosthetic abutment (Megagen) was individualized (parallelograph milled).

Figure no. 2. Prosthetic abutment.

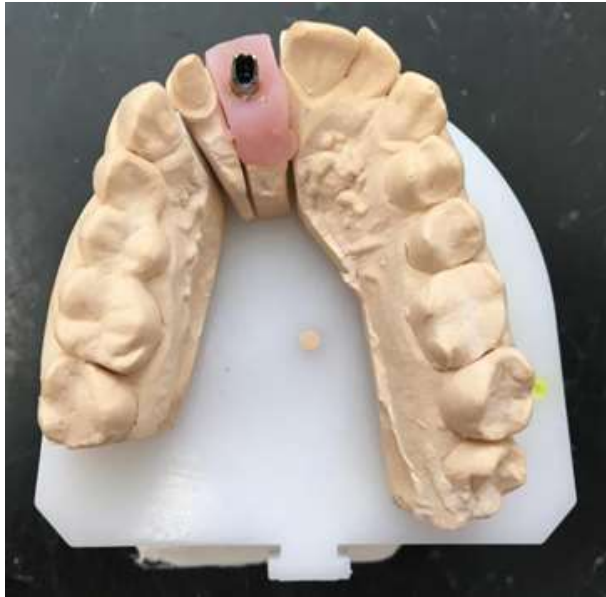

The master casts were CAD-CAM scanned using Ceramill Mind software and the design of the caps was made.

Physiognomic crowns were chosen from CAD-CAM library, then adjusted in volume to fit the dimension of future caps.

Laterality and propulsion movements were performed in the virtual articulator to check and correct the functionality of the capes, and to ensure there is enough space occlusal, labial, palatinal and proximal for layering the ceramic. Zirconia caps were CAD-CAM milled. 


\section{CLINICAL ASPECTS}

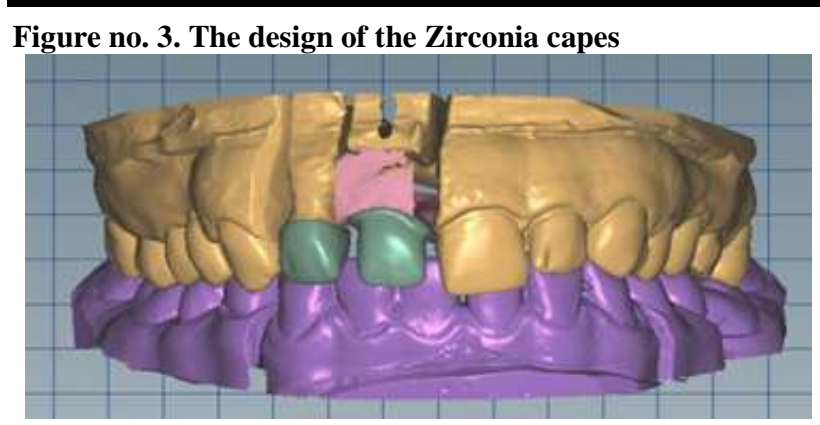

Figure no. 4. Zirconia capes

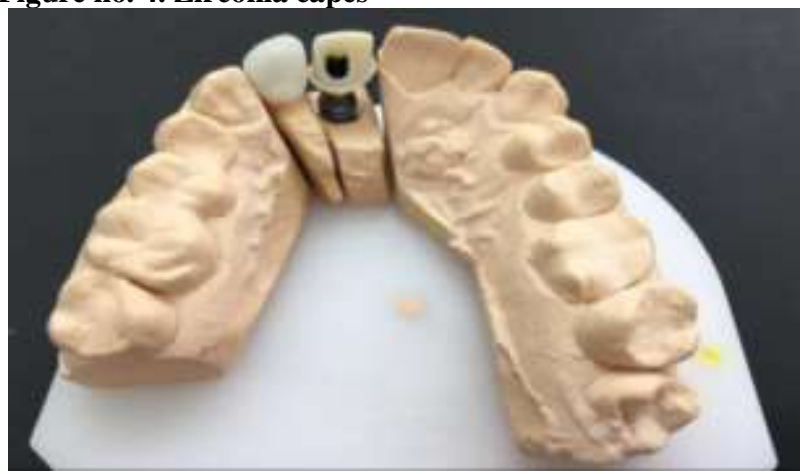

On Zirconia capes the wash layer was applied to facilitate the chemical connection between zirconia and ceramic. Wash layer was firing with corresponding program.

Next step consists of applying layers of ceramic for dentin and enamel (E-max from Ivoclar).

Ceramic was fired in ceramic oven with program designated for ceramic mass.

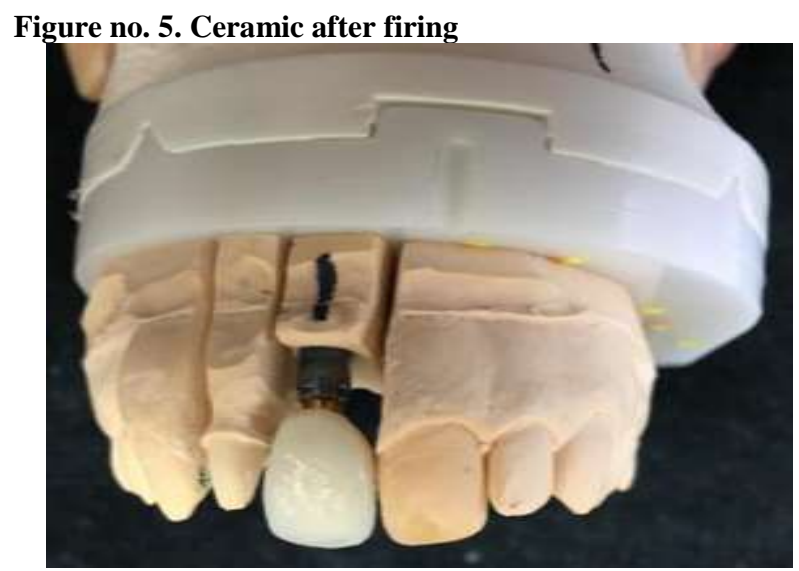

Figure no. 6. The crowns in final stage oral view

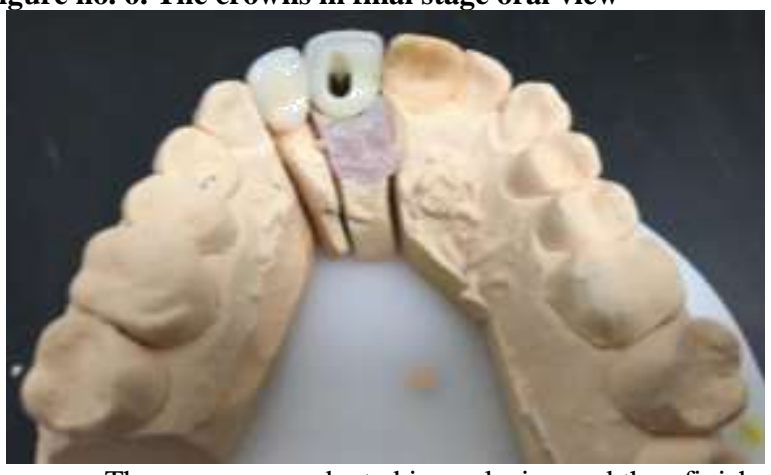

The crown was adapted in occlusion and then finished. The last step in performing the prosthetic restoration in the dental laboratory was the application and firing in the oven of the glaze.

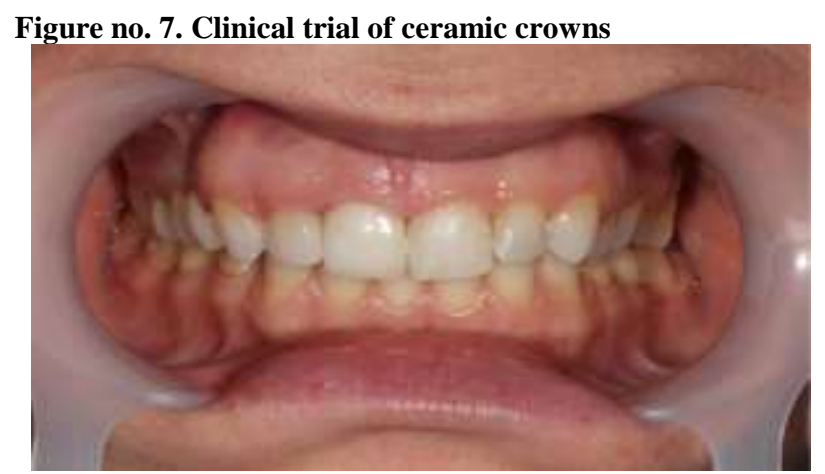

Fixed prosthetic restorations on the implant can be cement retained or screw retained. Cement retained procedure can be achieved in all clinical cases. The disadvantage of this method is that the implant and the surrounding tissues cannot be checked periodically by direct analysis.

Screw retained restorations have a more limited use, especially when the access to the fixing screw must be in a visible area, which would reduce the degree of aesthetics. Otherwise, the use of this retention technique allows that in the periodic control sessions or when it is the case, a direct control of the peri-implant tissues can be performed, as well as possible corrections of the restorations.

For these reasons, the knowledge and proper use of these types of restorations will be a major advantage especially for the patient, prolonging the life of prosthetic restorations and improving oral health.

\section{CONCLUSIONS}

1. Restoring the continuity of the dental arch is essential for the integrity of the dento-maxillary system and its functions;

2. Prosthetic restorations fixed on the dental implant allow the artificial reconstruction of the crown and the root of the teeth, without grinding the neighboring teeth;

3. Prosthetic restorations on ceramic implants on Zirconia structure are considered the most aesthetic prosthetic works, accurately rendering the color, translucency and shape of the tooth;

4. Ceramic and zirconium oxide dental materials have excellent biocompatibility;

5. Screw-retained prosthetic restorations on the implant are one of the best ways to restore not only aesthetically, but also the advantage of having access to dental implants at any time and solve a prosthetic complication.

Acknowledgement:

In this article, all the authors have equal contribution with the first author.

\section{REFERENCES}

1. Cristache $\mathrm{C}$, Burlibașa $\mathrm{M}$, Cristache $\mathrm{G}$ et al. Zirconia and its biomedical applications. Metalurgia International. 2011;XVI(7):18-23.

2. David VD. Restaurările protetice fixe. Editura Arvis Press, Bucuresti; 2006

3. Bratu D. Coroana mixtă. Editura Signata, Timișoara; 1992.

4. Rândașu I. Restaurări protetice dentare fixe. Editura Meteor Press; 2006.

5. Mocuța D, Popovici IA, Burlibasa L, Cristache G, Sfeatcu $\mathrm{R}$, Bodnar T. Impact of the living conditions on population health. Metalurgia International. 2009;14:17-19.

6. Burlibasa L, Chifiriuc MC, Lungu MV, Lungulescu EM, Mitrea S, Sbarcea G, Popa M, Marutescu L, Constantin N, 


\section{CLINICAL ASPECTS}

Bleotu C, Hermenean A. Sythesis, physico-chemical characterization, antimicrobial activity and toxicological featurs of $\mathrm{Ag}-\mathrm{ZnO}$ nanoparticles, Arabian Journal of Chemistry. 2020;13(1):4180-4197.

7. Burlibașa M, Cernuşcă-Mițariu M, Cernușcă-Mițariu S, Mițariu M, Malița M. Theoretical and practical aspects related to biomaterials decontamination in dental medicine (with reference to dental prosthetics). Metalurgia International. 2013;XVIII(4):261-267.

8. Mocuta D, Popovici LR, Dumitriu AS, Burlibaşa L, Ionescu CA, Sfeatcu R. Life quality-condition of social welfare. Metalurgia International. 2009;14:62-64.

9. Burlibașa M, Muntianu L, Tănase G, Bucur MB, Comes CA, Ionescu CA. Study on microbial contamination of biomaterials in medical practice. Metalurgia International. 2010;XV(Spec. Issue 2):163-166.

10. Ispas DC, Eftene OA, Burlibaşa M, Bucur MB, Tănase G, Cristache CM. Implications of titanium in orthodontics and dental facial orthopedics. Metalurgia International. 2011;XVI(10):72-74

11. Tănase G, Burlibașa M, Muntianu L, Simion I, Bucur MB, Ionescu CA. Testing the antibacterial potential of biomaterials in medical practice. Metalurgia International. 2010;XV(Spec. Issue 2):160-162.

12. Burlibașa M, Tănase $G$, Muntianu L, Murgu AI, Teodorescu E, Malița C. Quality of life, a multidisciplinary concept with economic and social impacts in medical practice. Metalurgia International. 2010;XV(Spec. Issue 4):88-90.

13. Burlibașa M, Cernușcă-Mițariu M, Burcea CC, Mițariu M, Ferechide D. Halogen compounds - theoretical, physiological and practical aspects regarding the decontamination, disinfection and sterilisation of instruments and biomaterials in dental medicine practice. Metalurgia International. 2012;XVIII(Spec. Issue 3):54-57.

14. Eșian D, Man A, Burlibașa L, Burlibașa M, Perieanu MV, Bică C. Salivary level of Streptococcus mutans and Lactobacillus spp. related to a high risk of caries disease. Rom Biotechnol Lett. 2017;22(2):12496-12503. 